\title{
Associations between abnormal vitamin D metabolism pathway function and non-small cell lung cancer
}

\author{
NAN GE $^{1 *}$, XIU-MEI CHU ${ }^{1 *}$, YUN-PENG XUAN ${ }^{1}$, DUN-QIANG REN ${ }^{2}$, \\ YONGJIE WANG $^{1}$, KAI MA ${ }^{1}$, HUI-JIANG GAO ${ }^{1}$ and WEN-JIE JIAO ${ }^{1}$ \\ Departments of ${ }^{1}$ Thoracic Surgery and ${ }^{2}$ Respiratory Medicine, The Affiliated Hospital \\ of Qingdao University, Qingdao, Shandong 266000, P.R. China \\ Received July 13, 2016; Accepted August 1, 2017
}

DOI: $10.3892 / \mathrm{ol} .2017 .7162$

\begin{abstract}
Lung cancer is a type of malignant tumor derived from the respiratory system, which is the leading cause of cancer-associated mortality worldwide, of which $\sim 80 \%$ of cases are attributable to non-small cell lung cancer (NSCLC). A previous study demonstrated that $1 \alpha, 25$-Dihydroxyvitamin $\mathrm{D}_{3}\left(1 \alpha, 25(\mathrm{OH})_{2} \mathrm{D}_{3}\right)$, derived from the vitamin $\mathrm{D}$ metabolic pathway contributes an antitumor effect. Aberrant expression of the essential enzyme encoding genes, Cytochrome P450 Family 27 Subfamily A Member 1 (CYP27A1), Cytochrome P450 Family 27 Subfamily B Member 1 (CYP27B1), and Cytochrome P450 Family 24 Subfamily A Member 1 (CYP24A1) may be associated with lung cancer. However, a lack of evidence exists concerning the association between CYP27A1, CYP27B1, CYP24A1 expression and NSCLC. The aim of the present study was to investigate the functions of CYP27A1, CYP27B1 and CYP24A1 expression in NSCLC. Lung cancer tissue and para-carcinoma control tissue were collected from patients with NSCLC. Reverse transcription-quantitative polymerase chain reaction was applied to analyze $C Y P 27 A 1, C Y P 27 B 1$ and $C Y P 24 A 1$ mRNA expression in lung cancer tissues. An association analysis was performed between the aforementioned metabolic enzymes and patients with NSCLC age, gender, tumor node metastasis (TNM) stage, pathological type, differentiation and prognosis. CYP27B1 and $C Y P 24 A 1 \mathrm{mRNA}$ were upregulated in NSCLC compared with controls $(\mathrm{P}<0.05)$. However, no significant differences in CYP27A1 expression were observed between NSCLC and
\end{abstract}

Correspondence to: Dr Wen-Jie Jiao, Department of Thoracic Surgery, The Affiliated Hospital of Qingdao University, 16 Jiangsu Road, Qingdao, Shandong 266000, P.R. China

E-mail:wenjiejiao220@sina.com

${ }^{*}$ Contributed equally

Key words: vitamin D, Cytochrome P450 Family 27 Subfamily A Member 1, Cytochrome P450 Family 27 Subfamily B Member 1, Cytochrome P450 Family 24 Subfamily A Member 1, non-small cell lung cancer, prognosis control. In addition, $C Y P 24 A 1$ expression was not associated with age, sex, smoking or TNM stage, but was associated with pathological type, differentiation and prognosis $(\mathrm{P}<0.05)$. $C Y P 27 B 1$ expression was significantly associated with TNM stage, differentiation, and prognosis, but not age, sex, smoking or pathological type. In conclusion, $C Y P 27 B 1$ and $C Y P 24 A 1$ may be considered as independent prognostic factors of NSCLC and may be novel therapeutic targets to assist clinical diagnosis, treatment and prognosis of the disease.

\section{Introduction}

Lung cancer is a type of malignant tumor derived from the respiratory system that is further classified into non-small cell lung cancer (NSCLC) and small cell lung cancer (SCLC). NSCLC accounts for $\sim 80 \%$ of lung cancer cases (1). NSCLC includes squamous cell carcinoma, adenocarcinoma and large cell carcinoma; of which adenocarcinoma presents with an increased onset. Adenocarcinoma demonstrates a reduced degree of malignancy compared with SCLC. The clinical symptoms of NSCLC differ depending on tumor size, location and metastatic range (2), and early NSCLC is often insidious, producing no visible symptoms until the disease is at an advanced stage. Due to the high degree of malignancy and rapid progression, the majority of patients are already in the mid-late stage of disease by the time of diagnosis. At this advanced stage of disease, surgical procedures are of no benefit to patients and therefore lung cancer is the principal cause of cancer-associated mortality worldwide $(3,4)$. Due to the changes of lifestyle and environmental pollution aggravation, lung cancer presents an increasing rate of mortality, and younger trend $(5,6)$. As the occurrence and development of lung cancer is multi-factorial, polygenic and multi-level process, there is still a requirement for an accurate diagnosis method in the early stages. However, the effects of treatments for advanced lung cancer are not favorable, with a poor prognosis $(7,8)$. Thus, early detection, early diagnosis, and early treatment are essential to improve the quality of life and survival of patients with lung cancer.

In previous years, vitamin $\mathrm{D}$ has been demonstrated to exert a range of biological functions, which include promoting calcium absorption, maintaining bone formation and reducing tumor occurrence and development $(9,10)$. Ultraviolet irradiation and appropriate vitamin $\mathrm{D}$ intake help reduce tumor 
incidence, including breast cancer, prostate cancer, lung cancer and colon cancer $(11,12)$. Conversely, Vitamin D deficiency is associated with an increased incidence of cancer, suggesting that vitamin D content is negatively associated with tumor progression. The primary sources of vitamin $\mathrm{D}$ are nutritional or from sunlight. $1 \alpha, 25$-Dihydroxyvitamin $\mathrm{D}_{3}\left(1 \alpha, 25(\mathrm{OH})_{2} \mathrm{D}_{3}\right)$ is the main active metabolite of vitamin $\mathrm{D}$ which can inhibit lung cancer cell proliferation, activation and progression through promoting apoptosis $(13,14)$. However, $1 \alpha, 25(\mathrm{OH})_{2} \mathrm{D}_{3}$ requires activation by the vitamin $\mathrm{D}$ metabolic pathway (15). Therefore, it is postulated that the aberrant expression of the essential enzymes CYP27A1, CYP27B1, and CYP24A1 may be associated with lung cancer. However, no previous research has been conducted to clarify the association between CYP27A1, CYP27B1 and CYP24A1 expression with NSCLC. The aim of the present study was to investigate $C Y P 27 A 1$, CYP27B1, and CYP24A1 expression in NSCLC.

\section{Materials and methods}

Patient selection. A total of 180 patients with NSCLC identified by pathological diagnosis were enrolled in the present study from the Affiliated Hospital of Qingdao University (Qingdao, China) between October 2013 and October 2015. All the selected patients with NSCLC received surgical treatment and included 92 males and 88 females. The age of the patients ranged between 45-87 years, with an average of $62.2 \pm 6.1$ years of age. A total of 62 cases were diagnosed at stage I, 57 cases at stage II, 34 cases at stage III and 27 cases at stage IV of the disease. Pathologically, 51 patients presented with squamous cell carcinoma, 82 patients with adenocarcinoma and 47 patients with large cell carcinoma. There were 42 cases of poor differentiation, 71 cases of moderate differentiation, and 67 cases of well differentiation. Inclusion criteria for the study were as follows: All subjects were newly diagnosed with lung cancer; all subjects received surgery for the first time; no chemotherapy or radiotherapy was conducted prior to surgery; all subjects had signed an informed consent prior to the study. Exclusion criteria were as follows: Recurrent lung cancer; previously received surgery; previously received chemotherapy or radiotherapy; combined with other disease, including infectious disease, malignant tumor, severe diabetes, severe renal and liver disease, pulmonary fibrosis, bone metabolic disease and systemic autoimmune disease. Cancer tissues and para-carcinoma tissues (defined as controls) were collected and stored at $-80^{\circ} \mathrm{C}$. The experimental protocols for the present study were pre-approved by the Ethical Committee of the Affiliated Hospital of Qingdao University and written informed consent was obtained from all patients prior to the study.

Chemicals and reagents. The RNA extraction kit and reverse transcription kit were from R \& D systems, Inc. (Minneapolis, $\mathrm{MN}, \mathrm{USA}$ ). Other common reagents were from Sangon Biotech Co., Ltd., (Shanghai, China). Real time PCR kit was from Thermo Fisher Scientific, Inc., (Waltham, MA, USA). The real time PCR amplifier was from ABI (Applied Biosystems; Thermo Fisher Scientific, Inc.). DNA amplifier was the PE Gene Amp PCR System 2400 (Applied.Biosystems; Thermo Fisher Scientific, Inc.).
Reverse transcription quantitative polymerase chain reaction $(R T-q P C R)$. Total RNA was extracted from patient lung tissues using TRIzol ${ }^{\circledR}$ reagent, according to the manufacturer's protocol. Total RNA was reverse transcribed to cDNA using Superscript III reverse transcriptase (Invitrogen; Thermo Fisher Scientific, Inc.). qPCR was performed to detect CYP24A1, CYP27A1 or CYP27B1 relative gene expression using a qPCR kit (Power SYBR ${ }^{\mathrm{TM}}$ Green PCR Master Mix; Thermo Fisher Scientific, Inc.), run on the Perkin Elmer Gene Amp PCR System 2400 thermal cycler. The reaction conditions were as follows; $92^{\circ} \mathrm{C}$ for $1 \mathrm{~min}$, followed by 35 cycles of $90^{\circ} \mathrm{C}$ for $30 \mathrm{sec}, 58^{\circ} \mathrm{C}$ for $50 \mathrm{sec}$ and $72^{\circ} \mathrm{C}$ for $35 \mathrm{sec}$. Glyceraldehyde 3-phosphate dehydrogenase (GAPDH) was selected as an internal reference gene. Melting curve analysis was performed to verify the target specificity of primers. Relative gene expression levels were quantified using the $2^{-\Delta \Delta \mathrm{Cq}}$ method.

Clinical data collection. Patients' age, sex, clinical stage, pathological type, differentiation status and prognosis were recorded and followed up.

Western blot. Total proteins were extracted from tissues by the addition of RIPA lysis buffer (Thermo Fisher Scientific, Inc.) and incubated at $4^{\circ} \mathrm{C}$ for $30 \mathrm{~min}$, followed by centrifugation at $12,000 \mathrm{x} \mathrm{g}$ for $10 \mathrm{~min}$ at $4^{\circ} \mathrm{C}$. Supernatants were transferred to new tubes for quantification of extracted protein concentrations using a BCA assay. Total proteins $(20 \mu \mathrm{g})$ were separated on $8-12 \%$ SDS-PAGE gel, and transferred to a PVDF membrane. Membranes were blocked by incubation with $5 \%$ skimmed milk for $1 \mathrm{~h}$ at $25^{\circ} \mathrm{C}$. The membranes were incubated with primary antibodies, rabbit polyclonal to CYP24A1 (cat. no. ab96691, Abcam, Cambridge, UK), Rabbit polyclonal to CYP27A1 (cat. no. ab64889, Abcam) or Rabbit monoclonal to CYP27B1 (cat. no. EPR20271, Abcam), $(1: 1,000)$ at $4^{\circ} \mathrm{C}$ overnight. The following day, membranes were further incubated in horseradish peroxidase-conjugated goat anti-rabbit secondary antibody (cat. no. ab6721, Abcam; 1:1,000) at $37^{\circ} \mathrm{C}$ for $1 \mathrm{~h}$. Proteins were detected using enhanced chemiluminescence reagents (Thermo Fisher Scientific, Inc.).

Statistical analysis. Statistical analyses were performed using SPSS v.16.0 software (SPSS; Inc., Chicago, IL, USA) and data were presented as the mean \pm standard deviation. Multiple group comparisons were performed using one-way analysis of variance and Fishers's least significant difference test. Enumerate data were presented as percentage and compared by $\chi^{2}$ test. Survival was assessed by Kaplan-Meier analysis. A Cox proportional hazards regression model was used for univariate and multivariate analysis. $\mathrm{P}<0.05$ was considered to indicate a statistically significant difference.

\section{Results}

CYP24A1, CYP27A1 and CYP27B1 mRNA expression in lung cancer. qPCR was conducted to analyze $C Y P 24 A 1$ mRNA expression in cancer tissue compared with para-carcinoma control tissue. The results demonstrated that CYP24Al mRNA expression was significantly upregulated in cancer tissues compared with controls $(\mathrm{P}<0.05$; Fig. 1A). Conversely, 

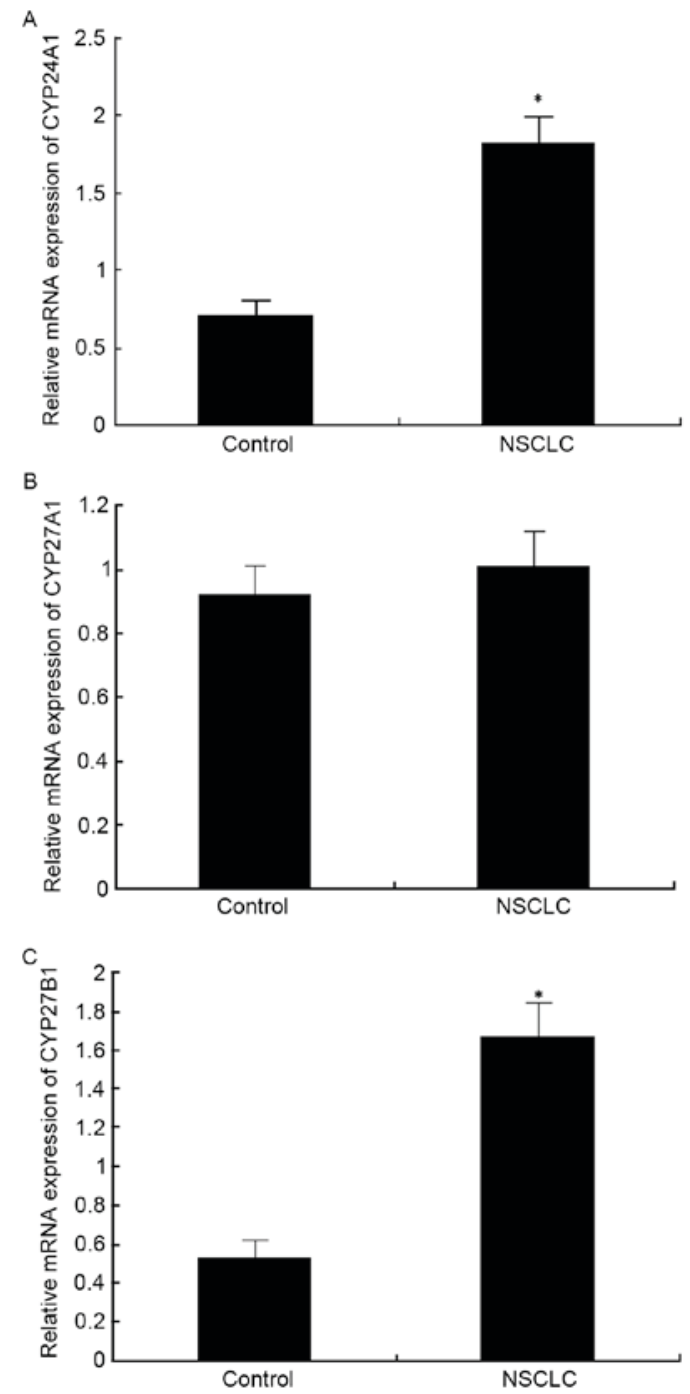

Figure 1. Gene expression levels of (A) CYP24A1, (B) CYP27A1 and (C) CYP27B1 in NSCLC and para-carcinoma tissues. "P $<0.05$ vs. control. CYP24A1, Cytochrome P450 Family 24 Subfamily A Member 1; CYP27A1, Cytochrome P450 Family 27 Subfamily A Member 1; CYP27B1, Cytochrome P450 Family 27 Subfamily B Member 1; NSCLC, non-small cell lung carcinoma.

CYP27A1 mRNA levels were marginally elevated in cancer tissues compared with controls, but no significant differences were observed (Fig. 1B). However, relative CYP27B1 mRNA expression levels were significantly upregulated in cancer tissues compared with para-carcinoma control tissues $(\mathrm{P}<0.05$; Fig. 1C).

CYP24A1, CYP27A1 and CYP27B1 protein expression in lung cancer. Comparable to the mRNA expression profiles, the protein expression of CYP24A1, CYP27A1 and CYP27B1 was elevated in cancer tissues compared with controls (Fig. 2).

CYP24A1 expression in patients with NSCLC with different pathological characteristics. qPCR and western blot analysis were used to detect CYP24A1 mRNA and protein expression in patients with NSCLC with different TNM stage, pathological type and differentiation status. The results from the present study suggested that CYP24A1 mRNA and protein levels increased with increasing TNM stages, although no statistical differences were observed. CYP24A1 levels were
A

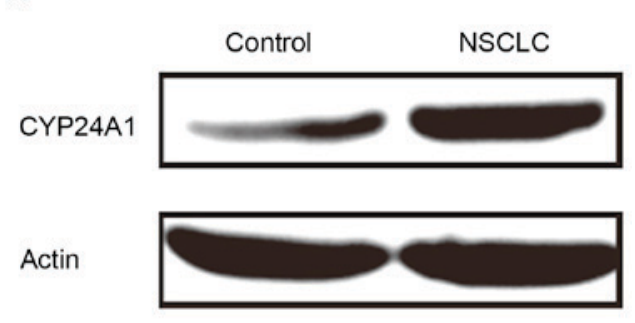

B

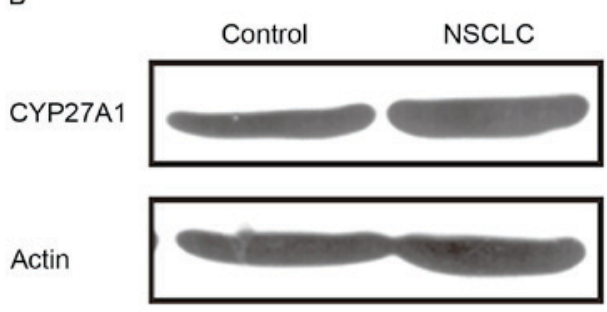

C

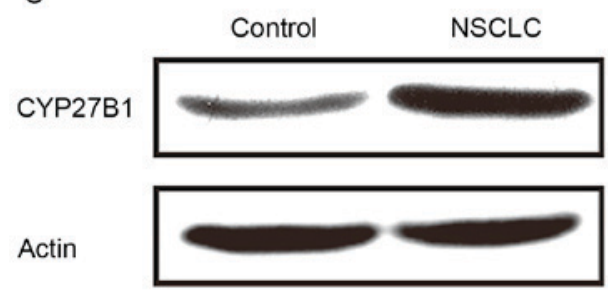

Figure 2. Western blot analysis of (A) CYP24A1, (B) CYP27A1 and (C) CYP27B1 protein expression in NSCLC and para-carcinoma tissues. CYP24A1, Cytochrome P450 Family 24 Subfamily A Member 1; CYP27A1, Cytochrome P450 Family 27 Subfamily A Member 1; CYP27B1, Cytochrome P450 Family 27 Subfamily B Member 1; NSCLC, non-small cell lung carcinoma.

markedly elevated in adenocarcinoma compared with squamous cell carcinoma and large cell carcinoma $(\mathrm{P}<0.05)$, but there was no significant difference between squamous and large cell carcinoma. CYP24A1 demonstrated increased expression in the poorly differentiated group, followed by the moderately differentiated compared with well-differentiated groups ( $\mathrm{P}<0.05$; Fig. 3A-C).

CYP27B1 expression in patients with NSCLC with different pathological characteristics. Analysis by qPCR and western blot was applied to measure CYP27B1 mRNA and protein expression in patients with NSCLC with different TNM stage, pathological type and differentiation status. The results from the present study revealed that CYP27B1 mRNA and protein levels were significantly elevated with increasing TNM stage (III and IV vs. I and II, P<0.05). However, the levels of CYP27B1 were not significantly different between different pathological types. Furthermore, CYP24A1 levels were increased in the poorly differentiated group, followed by moderately differentiated and well differentiated ( $\mathrm{P}<0.05$; Fig. 4A-C).

CYP24A1 and CYP27B1 mRNA expression levels in patients with NSCLC. The differences in CYP24Al and CYP27BI 
A

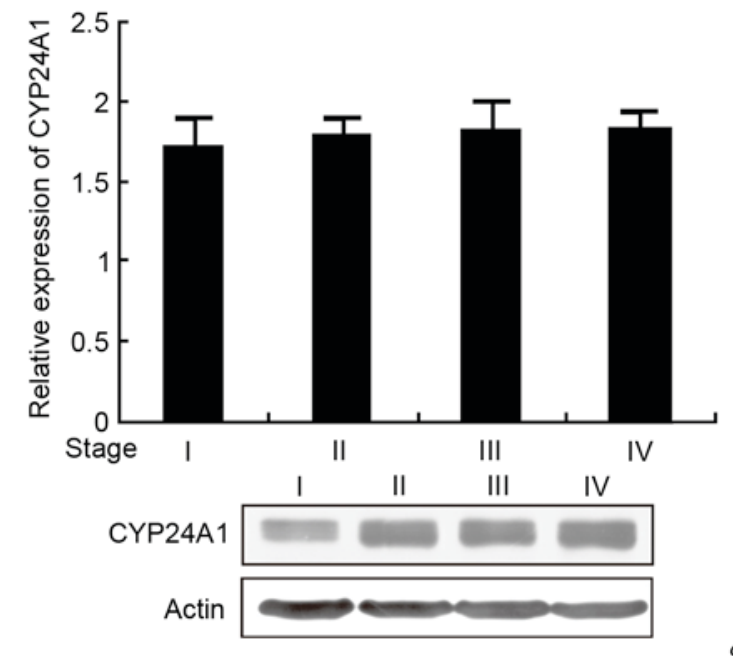

C

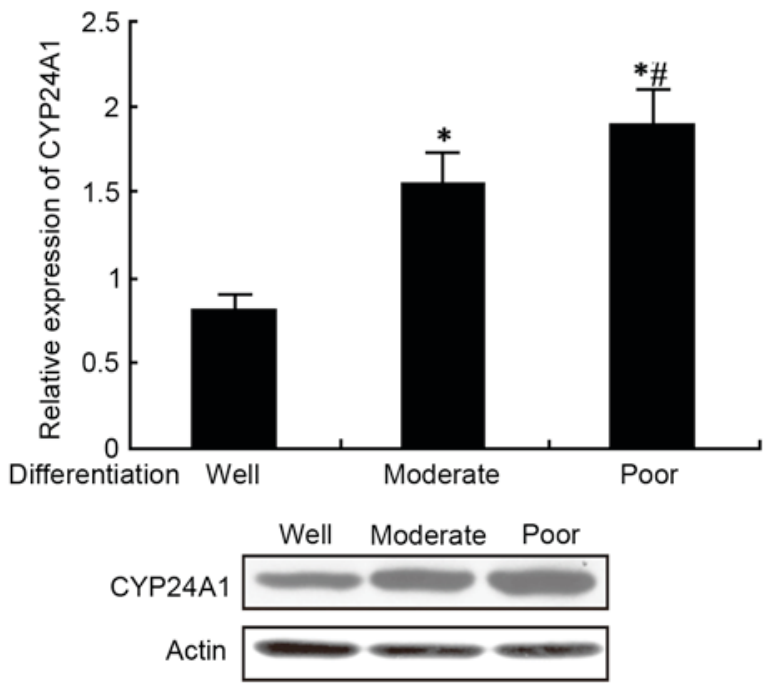

B

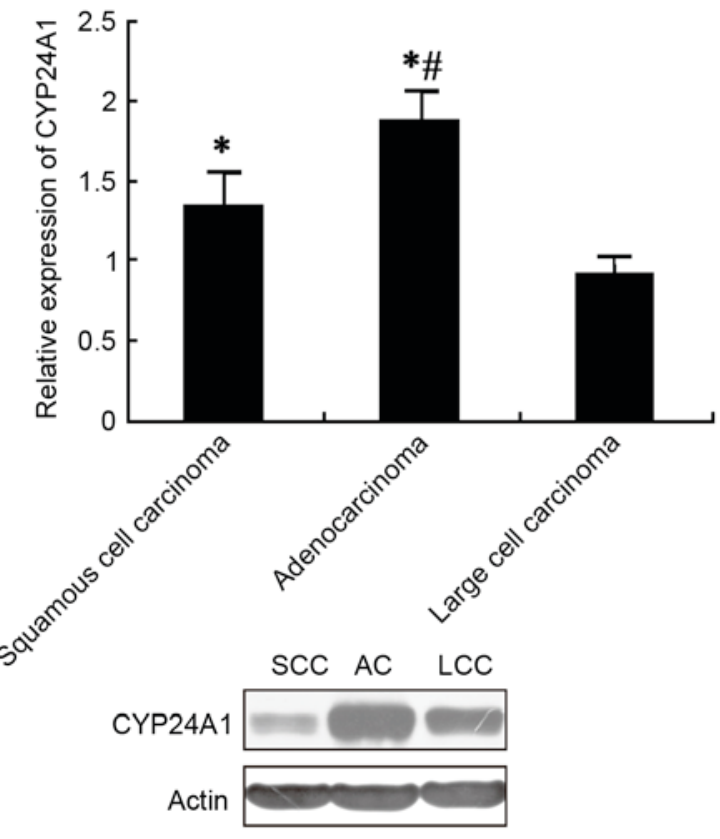

Figure 3. CYP24A1 mRNA and protein expression in patients with NSCLC with different pathological characteristics. (A) CYP24A1 mRNA and protein expression in patients with NSCLC with different TNM stages. (B) CYP24A1 mRNA and protein expression in patients with NSCLC with different pathological types ${ }^{*} \mathrm{P}<0.05$ vs. large cell carcinoma; ${ }^{*} \mathrm{P}<0.05$ vs. squamous cell carcinoma; (C) CYP24A1 mRNA and protein expression in NSCLC patients with different differentiation, ${ }^{*} \mathrm{P}<0.05$ vs. well differentiated; " $\mathrm{P}<0.05$ vs. moderately differentiated. CYP24A1, Cytochrome P450 Family 24 Subfamily A Member $1 ;$ NSCLC, non-small cell lung carcinoma.

mRNA expression in patients with NSCLC in association with age, sex, smoking and prognosis were compared. The results from the present study demonstrated that comparisons of CYP24A1 mRNA levels in patients with different age, sex and smoking presented no significant differences (Table II). In the prognosis analysis, patients with a survival time of $<5$ years had increased CYP24A1 mRNA levels compared with patients with a survival time $\geq 5$ years $(\mathrm{P}<0.05)$. Similar with $C Y P 24 A 1, C Y P 27 B 1$ mRNA levels demonstrated no significant differences in patients with different sex, gender or smoking status. In the prognosis analysis, $C Y P 27 B 1 \mathrm{mRNA}$ levels were increased in patients with a survival time of $<5$ years compared with a survival time of $\geq 5$ years $(\mathrm{P}<0.05$; Table II). To compare the differences in survival time between patients with varying $C Y P 24 A 1$ or $C Y P 27 B 1$ expression levels, Kaplan-Meier curve analysis was performed. Patients with increased $C Y P 24 A 1$ or $C Y P 27 B 1$ expression demonstrated a significantly shorter survival time compared with patients with reduced $C Y P 24 A 1$ or $C Y P 27 B 1$ expression (Fig. 5A and $\mathrm{B} ; \mathrm{P}<0.05)$.

\section{Discussion}

Lung cancer is the most common type of cancer and recurrent respiratory tract malignant tumor worldwide, and NSCLC accounts for the majority of lung cancer cases with poor prognosis (1). The average survival period for patients with NSCLC is short even following surgery, chemotherapy and radiotherapy (16). Following an in-depth investigation of lung cancer biology and pathogenesis over previous years, there have been notable advances in the diagnosis and treatment of lung cancer. However, the identification of specific biomarkers for the early diagnosis and prognosis of lung cancer is still required (17). The most bioactive metabolite of 
A

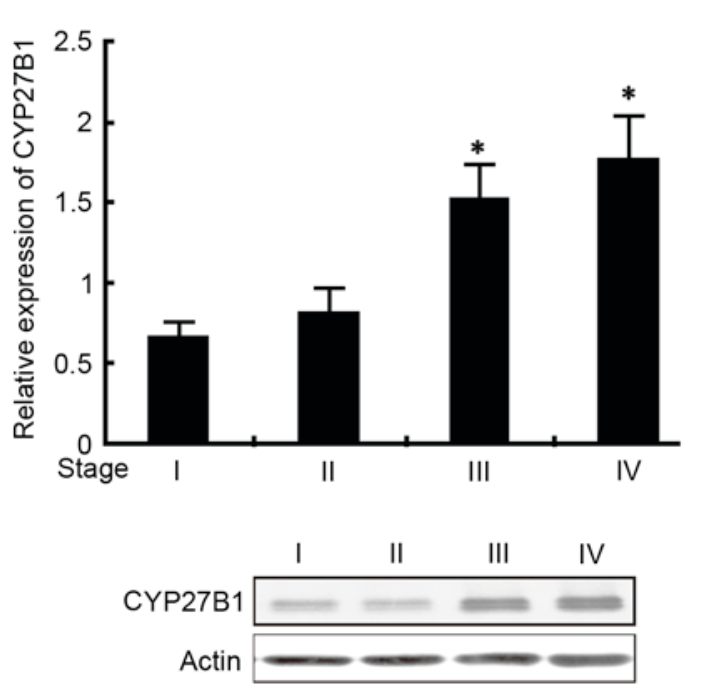

C

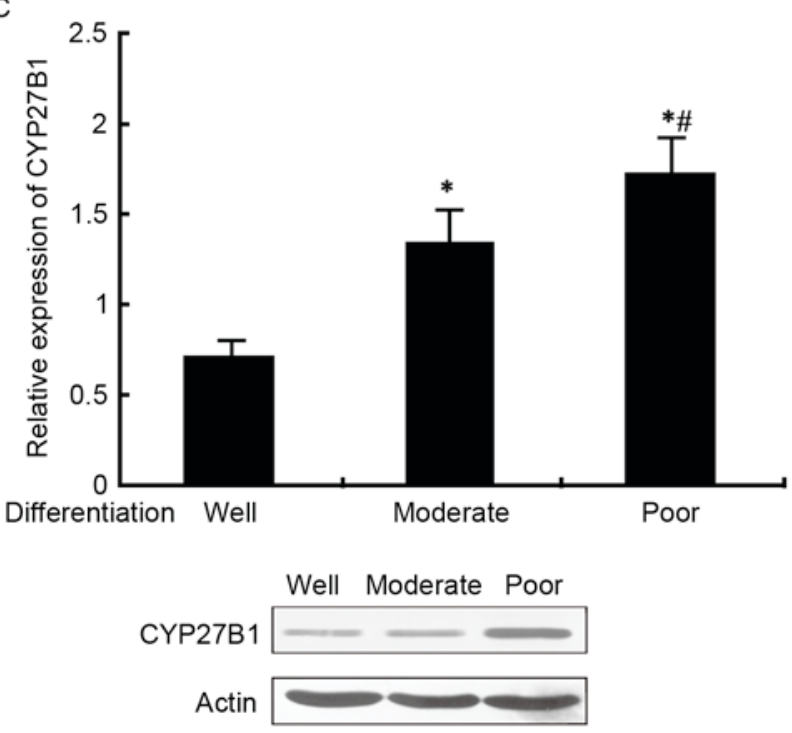

B

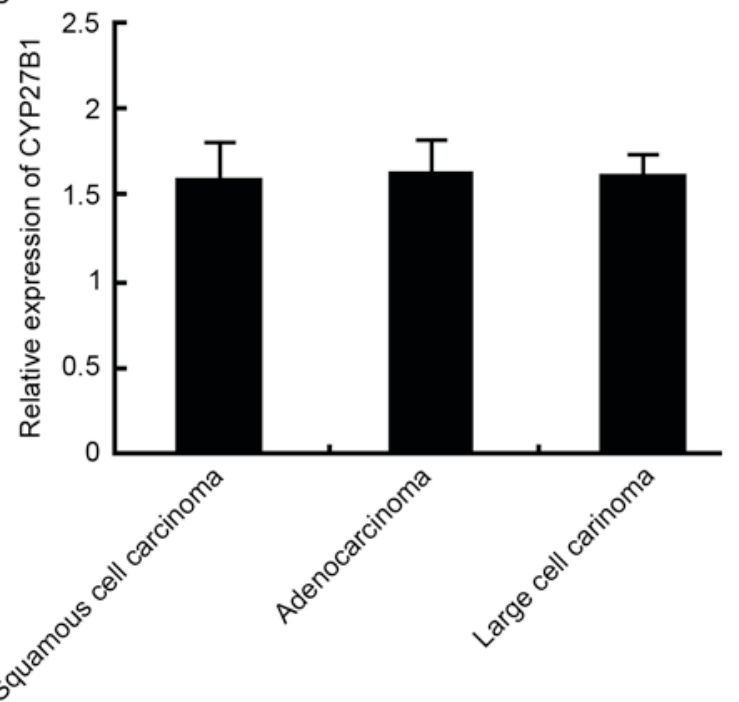

Figure 4. CYP27B1 mRNA and protein expression in patients with NSCLC with different pathological characteristics. (A) CYP27B1 mRNA and protein expression in patients with NSCLC with different TNM stages. (B) CYP27B1 mRNA and protein expression in patients with NSCLC with different pathological types, ${ }^{*} \mathrm{P}<0.05$, vs. large cell carcinoma; ${ }^{~} \mathrm{P}<0.05$ vs. squamous cell carcinoma; (C) CYP27B1 mRNA and protein expression in patients with NSCLC with different differentiation status, "P $<0.05$ vs. well differentiated; ${ }^{*} \mathrm{P}<0.05$ vs. moderately differentiated. CYP27B1, Cytochrome P450 Family 27 Subfamily B Member 1; NSCLC, non-small cell lung carcinoma.

vitamin $\mathrm{D}, 1 \alpha, 25(\mathrm{OH})_{2} \mathrm{D}_{3}$ has been confirmed to contribute various non-endocrine functions in addition to maintaining calcium stability; including anti-proliferative activity, induction of cell differentiation, promotion of cell cycle stagnation and apoptosis, inhibiting cytopoiesis and regulating tumor occurrence and development $(18,19)$. Vitamin D generates $1 \alpha, 25(\mathrm{OH})_{2} \mathrm{D}_{3}$ through the metabolic pathway. CYP27A1, mainly expressed in the liver and intestinal tract, encodes for 25-hydroxylase which metabolizes vitamin D to $1,25(\mathrm{OH}) \mathrm{D}(20)$. CYP27B1, widely expressed in multiple organs, encodes 25-hydroxy vitamin D 1- $\alpha$ hydroxylase to catalyze $1,25(\mathrm{OH}) \mathrm{D}$ to active $1 \alpha, 25(\mathrm{OH})_{2} \mathrm{D}_{3}(21)$. CYP24A1 encodes 25-hydroxy vitamin D3-24-hydroxylase that converts active metabolites to inactive 24,25-dihydroxy vitamin D (21). Thus, CYP27A1, CYP27B1, and CYP24A1 are three key enzymes in the vitamin D metabolic pathway. However, the association between CYP27A1, CYP27B1, and CYP24A1 and NSCLC have not been fully elucidated.

CYP27A1, CYP27B1, and CYP24A1 belong to the cytochrome P450 (CYP450) family. CYP450 is an important microsomal multi-functional oxidase family of hemoglobin enzymes. CYP450 is expressed in various tissues and organs, and has a variety of biological functions, including oxidation and metabolism of endogenous and exogenous substances. Previous studies have demonstrated that CYP24A1 is overexpressed in skin (22), colon (23), ovarian (24), prostate (25) and lung cancer (26). It promotes tumorigenesis through the stimulation of signaling pathways and is associated with poor prognosis $(27,28)$. However, there is still a lack of evidence to support the association of CYP27A1 and CYP27B1 with lung cancer. The present study confirmed that $C Y P 27 B 1$ and 
Table I. Primer sequences for reverse transcription-quantitative polymerase chain reaction.

\begin{tabular}{lll}
\hline Gene & \multicolumn{1}{c}{$($ Forward 5'-3') } & \multicolumn{1}{c}{$($ Reverse 5'-3') } \\
\hline GADPH & \multicolumn{1}{c}{ AGTGCCAGCCTCGTCTCATAG $24 A 1$} & CGTTGAACTTGCCGTGGGTAG \\
$C Y P 27 A 1$ & GCCGTATTTAAAAGCCTGTCTGAA & ACCTGGGTATTTAGCATGAGCACTG \\
$C Y P 27 B 1$ & CGTATTGCAATGTCTGAGCCA & ACCTGAATACCTGAATGTACCT \\
& TATTGCCGTAGCCAATGTCTG & GGTACCTGAATGACCTGAATGCA
\end{tabular}

Table II. Comparison of $C Y P 24 A 1$ and $C Y P 27 B 1$ mRNA expression in patients with NSCLC in association with age (60 years-cut off value), sex, smoking and survival time (5 years-cut off value).

\begin{tabular}{llc}
\hline Variable & $\begin{array}{c}\text { CYP24A1 } \\
\text { mRNA levels }\end{array}$ & $\begin{array}{c}C Y P 27 B 1 \\
\text { mRNA levels }\end{array}$ \\
\hline Age, years & & \\
$<60$ & $1.78 \pm 0.31$ & $1.61 \pm 0.25$ \\
$\geq 60$ & $1.82 \pm 0.19$ & $1.68 \pm 0.91$ \\
Sex & & \\
Male & $1.81 \pm 0.55$ & $1.71 \pm 0.61$ \\
Female & $1.79 \pm 0.13$ & $1.65 \pm 0.53$ \\
Smoking & & \\
No & $1.80 \pm 0.17$ & $1.62 \pm 0.47$ \\
Yes & $1.83 \pm 0.22$ & $1.70 \pm 0.74$ \\
Survival time, years & & \\
$<5$ & $1.87 \pm 0.91$ & $1.79 \pm 0.78$ \\
$\geq 5$ & $1.32 \pm 0.26^{\mathrm{a}}$ & $1.21 \pm 0.15^{\mathrm{a}}$ \\
\hline
\end{tabular}

${ }^{\text {aP }}<0.05$. CYP24A1, Cytochrome P450 Family 24 Subfamily A Member 1; CYP27B1, Cytochrome P450 Family 27 Subfamily B Member 1.

CYP24A1 mRNA expression were significantly elevated in patients with NSCLC. CYP24Al expression was not associated with age, sex, smoking or TNM stage, but with pathological type, differentiation and prognosis. CYP27B1 expression was significantly associated with TNM stage, differentiation and prognosis, as opposed to age, sex, smoking status and pathological type. However, a previous study revealed that increased $C Y P 27 B 1$ expression in tumors was significantly associated with improved overall survival (29). However, this association was attenuated when covariates and confounding variables were adjusted in the regression model. The discrepancies between the present study and the Kong et al (29) study may be due to the clinical characteristics of enrolled patients, including age, sex and disease stage.

It has been suggested that the effect of $1 \alpha, 25(\mathrm{OH})_{2} \mathrm{D}_{3}$ on tumor cell development was dependent on CYP27B1 and CYP24A1 activity. In addition, the polymorphism of CYP24A1 and CYP27B1 has been demonstrated to be involved in the modulation of vitamin D metabolism in colon cancer, evidenced by marked changes in enzymatic activity in colon
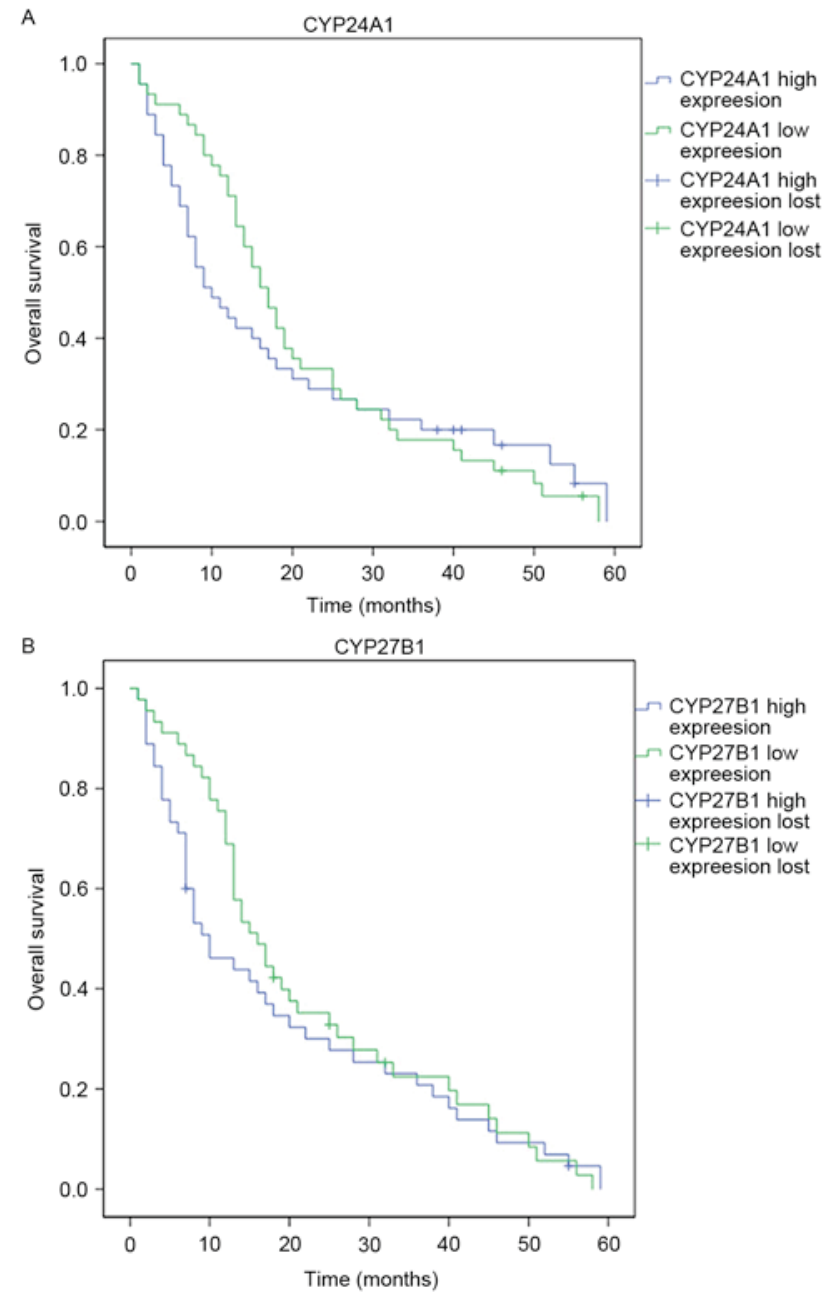

Figure 5. Kaplan-Meier curve analysis of overall survival in patients with high or low expression of (A) CYP24A1 or (B) CYP27B1. CYP24A1, Cytochrome P450 Family 24 Subfamily A Member 1; CYP27B1, Cytochrome P450 Family 27 Subfamily B Member.

cancer cells, resulting from the polymorphism of $C Y P 24 A 1$ and $C Y P 27 B 1$ (30). These alterations may possibly cause differential $1,25 \mathrm{D}$ exposure in colonic cells, which may render individuals more susceptible to the development of colon cancer.

In conclusion, CYP27B1 and CYP24A1 may be treated as independent prognostic factors of NSCLC, and may be new therapeutic targets to assist clinical diagnosis, treatment and prognosis of disease. However, the exact mechanism by how CYP27B1 and CYP24A1 are involved in the pathogenesis of NSCLC remains unclear and requires further investigation. 


\section{Acknowledgements}

The present study was funded by an Academic Fund for Young Scientist Award, The Affiliated Hospital of Qingdao University, Qingdao, China (grant no. 2208).

\section{References}

1. Gudala S, Khan U, Kanungo N, Bandaru S, Hussain T, Parihar M, Nayarisseri A and Mundluru HP: Identification and pharmacological analysis of high efficacy small molecule inhibitors of EGF-EGFR interactions in clinical treatment of non-small cell lung carcinoma: A computational approach. Asian Pac J Cancer Prev 16: 8191-8196, 2015.

2. Xia M, Duan ML, Tong JH and Xu JG: MiR-26b suppresses tumor cell proliferation, migration and invasion by directly targeting COX-2 in lung cancer. Eur Rev Med Pharmacol Sci 19: 4728-4737, 2015.

3. Paz-Ares L,Hirsh V,Zhang L, de Marinis F, Yang JC, Wakelee HA, Seto T, Wu YL, Novello S, Juhász E, et al: Monotherapy administration of sorafenib in patients with non-small cell lung cancer (MISSION) trial: A phase III, multicenter, placebo-controlled trial of sorafenib in patients with relapsed or refractory predominantly nonsquamous non-small-cell lung cancer after 2 or 3 previous treatment regimens. J Thorac Oncol 10: 1745-1753, 2015.

4. Guerrera F, Tabbò F, Bessone L, Maletta F, Gaudiano M, Ercole E, Annaratone L, Todaro M, Boita M, Filosso PL, et al The Influence of tissue ischemia time on RNA integrity and patient-derived xenografts (PDX) engraftment rate in a non-small cell lung cancer (NSCLC) biobank. PLoS One 11: e0145100, 2016.

5. Tai CJ, Wang CK, Tai CJ, Tzao C, Lien YC, Hsieh CC, Hsieh CI, $\mathrm{Wu} \mathrm{HC}$, Wu CH, Chang CC, et al: Evaluation of safety and efficacy of salvage therapy with sunitinib, docetaxel (Tyxane) and cisplatinum followed by maintenance vinorelbine for unresectable/metastatic nonsmall cell lung cancer: Stage 1 of a simon 2 stage clinical trial [Corrected]. Medicine (Baltimore) 94: e2303, 2015.

6. Robinson AG, Young K, Balchin K, Owen T and Ashworth A: Reasons for palliative treatments in stage III non-small-cell lung cancer: What contribution is made by time-dependent changes in tumour or patient status? Curr Oncol 22: 399-404, 2015.

7. Sasaki S, Yoshioka Y, Ko R, Katsura Y, Namba Y, Shukuya T, Kido K, Iwakami S, Tominaga S and Takahashi K: Diagnostic significance of cerebrospinal fluid EGFR mutation analysis for leptomeningeal metastasis in non-small-cell lung cancer patients harboring an active EGFR mutation following gefitinib therapy failure. Respir Investig 54: 14-19, 2016.

8. Kepka L and Socha J: PET-CT limitations in early stage non-small cell lung cancer: To whom more aggressive approach in radiotherapy and surgery should be directed? J Thorac Dis 7: $1887-1890,2015$

9. Piotrowska A, Wierzbicka J, Nadkarni S, Brown G, Kutner A and Żmijewski MA: Antiproliferative activity of double point modified analogs of 1,25-dihydroxyvitamin $\mathrm{D}_{2}$ against human malignant melanoma cell lines. Int J Mol Sci 17: pii: E76, 2016.

10. Aguirre M, Manzano N, Salas Y, Angel M, Díaz-Couselo FA and Zylberman M: Vitamin D deficiency in patients admitted to the general ward with breast, lung, and colorectal cancer in buenos aires, argentina. Arch Osteoporos 11: 4, 2016.

11. Wen Y, Da M, Zhang Y, Peng L, Yao J and Duan Y: Alterations in vitamin $\mathrm{D}$ signaling pathway in gastric cancer progression: $\mathrm{A}$ study of vitamin D receptor expression in human normal, premalignant, and malignant gastric tissue. Int J Clin Exp Pathol 8: $13176-13184,2015$.

12. Vashi PG, Edwin P, Popiel B and Gupta D: The relationship between circulating 25-hydroxyvitamin $\mathrm{D}$ and survival in newly diagnosed advanced non-small-cell lung cancer. BMC Cancer 15: 1012, 2015.

13. Christakos S, Dhawan P, Verstuyf A, Verlinden L and Carmeliet G: Vitamin D: Metabolism, molecular mechanism of action, and pleiotropic effects. Physiol Rev 96: 365-408, 2016.
14. Khayatzadeh S, Feizi A, Saneei P and Esmaillzadeh A: Vitamin D intake, serum Vitamin D levels, and risk of gastric cancer: A systematic review and meta-analysis. J Res Med Sci 20: 790-796, 2015.

15. Hibler EA, Sardo Molmenti CL, Dai Q, Kohler LN, Warren Anderson S, Jurutka PW and Jacobs ET: Physical activity, sedentary behavior, and vitamin D metabolites. Bone 83: 248-255, 2016

16. Huang Z, Yi X, Luo B, Zhu J, Wu Y, Jiang W, Chu H, Yang Z, $\mathrm{Li} \mathrm{S}$, Zhu H, et al: Induced sputum deposition improves diagnostic yields of pulmonary alveolar proteinosis: A clinicopathological and methodological study of 17 cases. Ultrastruct Pathol 40: 7-13, 2016.

17. Ortakoylu MG,Iliaz S, Bahadir A, Aslan A, Iliaz R, Ozgul MA and Urer HN: Diagnostic value of endobronchial ultrasound-guided transbronchial needle aspiration in various lung diseases. J Bras Pneumol 41: 410-414, 2015 (In English, Portuguese).

18. Yin K, You Y, Swier V, Tang L, Radwan MM, Pandya AN and Agrawal DK: Vitamin D protects against atherosclerosis via regulation of cholesterol efflux and macrophage polarization in hypercholesterolemic swine. Arterioscler Thromb Vasc Biol 35: 2432-2442, 2015.

19. Fedorova OV, Zernetkina VI, Shilova VY, Grigorova YN, Juhasz O, Wei W, Marshall CA, Lakatta EG and Bagrov AY: Synthesis of an endogenous steroidal na pump inhibitor marinobufagenin, implicated in human cardiovascular diseases, is initiated by CYP27A1 via bile acid pathway. Circ Cardiovasc Genet 8: 736-745, 2015.

20. Gascon-Barré M, Demers C, Ghrab O, Theodoropoulos C, Lapointe R, Jones G, Valiquette L and Ménard D: Expression of CYP27A, a gene encoding a vitamin D-25 hydroxylase in human liver and kidney. Clin Endocrinol (Oxf) 54: 107-115, 2001.

21. Adams JS and Hewison M: Extrarenal expression of the 25-hydroxyvitamin D-1-hydroxylase. Arch Biochem Biophys 523: 95-102, 2012.

21. Mast N, Lin JB and Pikuleva IA: Marketed drugs can inhibit cytochrome P450 27A1, a potential new target for breast cancer adjuvant therapy. Mol Pharmacol 88: 428-436, 2015.

22. Brożyna AA, Jochymski C, Janjetovic Z, Jóźwicki W, Tuckey RC and Slominski AT: CYP24A1 expression inversely correlates with melanoma progression: Clinic-pathological studies. Int J Mol Sci 15: 19000-19017, 2014.

23. Horváth HC, Lakatos P, Kósa JP, Bácsi K, Borka K, Bises G, Nittke T, Hershberger PA, Speer G and Kállay E: The candidate oncogene CYP24A1: A potential biomarker for colorectal tumorigenesis. J Histochem Cytochem 58: 277-285, 2010.

24. Anderson MG, Nakane M, Ruan X, Kroeger PE and Wu-Wong JR: Expression of VDR and CYP24A1 mRNA in human tumors. Cancer Chemother Pharmacol 57: 234-240, 2006.

25. Whitlatch LW, Young MV, Schwartz GG, Flanagan JN, Burnstein KL, Lokeshwar BL, Rich ES, Holick MF and Chen TC: 25-Hydroxyvitamin D-1alpha-hydroxylase activity is diminished in human prostate cancer cells and is enhanced by gene transfer. J Steroid Biochem Mol Biol 81: 135-140, 2002.

26. Chen G, Kim SH, King AN, Zhao L, Simpson RU, Christensen PJ, Wang Z, Thomas DG, Giordano TJ, Lin L, et al: CYP24A1 is an independent prognostic marker of survival in patients with lung adenocarcinoma. Clin Cancer Res 17: 817-826, 2011.

27. Shui IM, Mondul AM, Lindström S, Tsilidis KK, Travis RC, Gerke T, Albanes D, Mucci LA, Giovannucci E and Kraft P; Breast and Prostate Cancer Cohort Consortium Group: Circulating vitamin $\mathrm{D}$, vitamin D-related genetic variation, and risk of fatal prostate cancer in the national cancer institute breast and prostate cancer cohort consortium. Cancer 121: 1949-1956, 2015.

28. Lee WR, Ishikawa T and Umetani M: The interaction between metabolism, cancer and cardiovascular disease, connected by 27-hydroxycholesterol. Clin Lipidol 9: 617-624, 2014.

29. Kong J, Xu F, Qu J, Wang Y, Gao M, Yu H and Qian B: Genetic polymorphisms in the vitamin D pathway in relation to lung cancer risk and survival. Oncotarget 6: 2573-2782, 2014.

30. Jacobs ET, Van Pelt C, Forster RE, Zaidi W, Hibler EA, Galligan MA, Haussler MR and Jurutka PW: CYP24A1 and CYP27B1 polymorphisms modulate vitamin D metabolism in colon cancer cells. Cancer Res 73: 2563-2573, 2013. 